Machado, L. D.

"O desafio ético da escrita"

\title{
O DESAFIO ÉTICO DA ESCRITA
}

\author{
Leila Domingues Machado \\ Universidade Federal do Espírito Santo
}

RESUMO: Na maioria das vezes a escrita "científica" deixa poucos rastros das inúmeras implicações que a teceu. As dúvidas, os impasses, as noites mal dormidas, as páginas em branco na tela do computador ficam para trás compondo uma memória que se quer esquecida ou uma ferida que se quer cicatrizada ou uma espécie de diário de "erros" superados. Essa escrita é "do que"? Essa escrita é "como"? Essa escrita é "para quê"? Pode-se, podemos, posso fazer uma escrita "higiênica", uma escrita neutra e distante acerca de alguma coisa. A razão no estilo cartesiano assegura métodos de pesquisa e, por conseguinte, também de escrita assépticos e tristes. São todos aqueles textos que nossos olhos percorrem por obrigação e que pouco depois esquecemos. São textos que não nos provocam, ou agradam ou desagradam, ou nos trazem alguma idéia ou nos deixam alguma indagação. Neste texto trazemos para análise algumas dessas questôes.

PALAVRAS-CHAVE: escrita científica, estilo cartesiano, métodos de pesquisa.

\section{THE ETHICAL CHALLENGE OF WRITING}

ABSTRACT: Most of times "scientific" writing leaves few tracks of the many implications that wove it. The doubts, the impasses, the nights badly slept, the blank pages on the computer screen are left behind composing a memory that wants itself forgotten, or a wound that wants itself healed, or a sort of "overcame erros" diary. What is this writing about? How is this writing? What is this writing for? It can be done, we can do, I can do an "hygienic" writing, a neutral and distant writing concerning something. Reason in the cartesian style assures methods of research and, therefore, also of aseptic and sad writing. They are all those texts our eyes go through for obligation and shortly afterwards we forget. They are texts that do not provoke or please or displease or bring us any idea or leave us any doubts. In this text we bring to analysis some of these issues.

KEYWORDS: scientific writing, cartesian style. 
Psicologia \& Sociedade; 16 (1): 146-150; Número Especial 2004

\section{NOTA DE ABERTURA}

Convencionou-se chamar uma certa escrita de "acadêmica" e elegê-la como a forma prioritária e reconhecida de expressão dos estudos e pesquisas realizados nas universidades. "Eu" escrevo, "nós" escrevemos ou escreve-"se" denotaria o estilo de cada um. Mas de que estilo se trata: lingüístico ou ético? Na maioria das vezes a escrita "científica" deixa poucos rastros das inúmeras implicações que a teceu. As dúvidas, os impasses, as noites mal dormidas, as páginas em branco na tela do computador ficam para trás compondo uma memória que se quer esquecida ou uma ferida que se quer cicatrizada ou uma espécie de diário de "erros" superados.

Essa escrita é "do quê"? Essa escrita é "como"? Essa escrita é "para que"? Pode-se, podemos, posso fazer uma escrita "higiênica", uma escrita neutra e distante acerca de alguma coisa. Escrita de um objeto separado e distinto de um sujeito. Nesse caso, "eu" ou "nós" ou "se" são apenas figuras de linguagem que denotam a originalidade e competência de um "eu" autor ou uma certa humildade do mesmo ou um apagamento de qualquer rastro de singularidade no discurso. No entanto, esse tipo de texto carrega muito pouco de uma potência de transformação. Por que? Talvez porque não haja paixão. A razão no estilo cartesiano assegura métodos de pesquisa e, por conseguinte, também de escrita assépticos e tristes. São todos aqueles textos que nossos olhos percorrem por obrigação e que pouco depois esquecemos. São textos que não nos tiram do lugar, que não nos provocam, ou agradam ou desagradam, ou nos trazem alguma idéia ou nos deixam alguma indagação.

Todavia, a escrita pode ter uma função etopoiética, ou melhor, uma função estética e política de criação de si. Não de criação de "eus" ou de demarcação de autorias e sim de alteridade, o desmanchar de modelos que reproduzimos quase como se fossem naturais. Modelos que perpetuamos como se gostássemos quando sequer percebemos quanto podem ser intoleráveis. A alteridade nos faz

1 Expressão de Plutarco utilizada por Foucault em: FOUCAULT, Michel. A escrita de si. In: O que éum autor? Tradução António Fernando Cascais; Edmundo Cordeiro. Portugal: Veja/Passagens, 1992, pág. 134. 
Machado, L. D.

"O desafio ético da escrita"

diferir, é desafio para a criação de uma escrita ética, criação de uma escrita de si, desafio que nos convida a transformarmo-nos em meio à própria escrita. Não se trata de um compromisso com "o belo", mas de um compromisso com a vida, com uma potência de solidariedade que nos força a abandonar os ressentimentos.

\section{UMA ESCRITA DE SI}

Misturar leitura e escrita. Recorrer alternadamente as duas e "temperar uma por meio da outra". Pois escrever demais cansa e as muitas leituras dispersam. Ir incessantemente de livro em livro sem criar com as tantas leituras um corpo, nos coloca frente ao perigo de sermos apenas passageiros da dispersão. De pouco adianta uma voracidade que nos faça descer livros da estante ou que nos faça consumir muitos livros que não serão sequer abertos. Com isso apaziguamos a ansiedade e nos distanciamos de uma batalha, que não é destruição, é um desassossego que nos ronda e nos sacode as certezas.

Muita agitação impede a processualidade das misturas, a criação de planos de consistência para o que foi lido ou para o que será escrito. Uma agitação que provoca incessantes mudanças, mas não faz a instabilidade estremecer as certezas. Ao contrário, parece nos colocar mais em um lugar de fragilidade, de surdez, de cegueira perante todos os acontecimentos. Nos desviamos para um futuro que não cria espessuras no presente e não guarda pontas de passado. Nos tornamos desejosos somente de supostas novidades e nos esquecemos de forjar composições.

Através da escrita podemos compor combinatórias com a diversidade dos materiais de expressão trazidos pelas leituras. Território ao qual podemos regressar e recolher-nos. Um exercício que procura se desvencilhar do perigo que a leitura infindável arrisca favorecer. Entretanto, essa escrita precisa ser uma prática da disparidade. Ao mesmo tempo, regrada e desejante. Um trabalho de avaliação e de escolha de elementos heterogêneos.

A escrita, então, torna-se exercício de um pensamento que não coincide com a razão, com a inteligência, com a erudição ou 
com o conhecimento da obra inteira de um autor. E também não coincide com um tipo de aprendizagem e de ensino que reivindicam a unidade doutrinal de uma escola.

Uma escrita que possa produzir disparidades nos conceitos, que os jogue na própria imanência do que afirmam. O importante é que possamos considerar um conceito como algo que nos força a pensar, algo que expande e torna complexas as questôes, e que, assim, seja produtivo em função das circunstâncias em que nos encontremos, que sejam éticos naquilo que fazem funcionar. E, assim, tentamos fazer o conceito se dobrar, se redobrar, se desdobrar em múltiplas afirmações.

A leitura nos percorre e não faz apenas parte de uma lembrança, torna-se nosso próprio corpo. É preciso que haja uma composição das consultas, das leituras e releituras, das escolhas, enfim, da vida, naquele que escreve e no que escreve. Trata-se de conectar fragmentos por meio da criação de um estilo de escrita. E o corpo que aí se cria, não é um corpo de doutrina, é o próprio corpo daquele que ao ser percorrido pelas leituras se apossou delas e faz sua afirmativa. A escrita pode transformar a coisa vista ou ouvida em batalhas. Ela transforma-se em um princípio de ação. Em contrapartida, aquele que escreve se transmuta em meio a esse emaranhado.

A escrita como encontro com a alteridade, como um desmanchar do Idêntico, a escrita como um 'outramento'. Uma estranheza. "Eu não sou eu nem sou outro, sou qualquer coisa de intermédio". ${ }^{2}$ Um outro de si, um outro de outro e, no entanto, não há nenhum 'eu' e nem nenhum outro, somente um 'entre'. "Não ser eu, toda gente, toda parte". ${ }^{3}$ A escrita percorrida por algo que não nos diz respeito e nos é próximo, por algo que se relaciona a nós e nos é distante. Algo que é o próprio desmanchar de mim mesmo. Algo que nos incita a inventar outras formas ao conjugarmos os tantos verbos da nossa vida. Um desafio, uma provocação, o ressoar de uma questão em nós: o que tenho escolhido fazer de mim?

2 CALCANHOTO, Adriana. O outro. In: Público. Produção: Dudu Marote. Direção Artística: Jorge Davidson. São Paulo: BMG, 2000. 1 CD. Faixa 7.

3 Frase de Fernando Pessoa que aparece na película: O CÉU DE LISBOA. Direção: Wiw Wenders. Produção:? Portugal; Alemanha, 1994. 1 filme (105) min).

4 Texto baseado em: FOUCAULT, Michel. A escrita de si. In: O que é um autor? Tradução António Fernando Cascais; Edmundo Cordeiro. Portugal: Veja/Passagens, 1992. 
Machado, L. D.

"O desafio ético da escrita"

\section{REFERENNCIAS}

BLANCHOT, Maurice. O espaço literário. Tradução Álvaro Cabral. Rio de Janeiro: Rocco, 1987. 278 p.

BLANCHOT, Maurice. El paso (no) más allá. Barcelona: Ediciones Piados, 1994. $168 \mathrm{p}$.

BLANCHOT, Maurice. A conversa infinita. Tradução Aurélio Guerra Neto. São Paulo: Escuta, 2001. 152 p.

CALCANHOTO, Adriana. O outro. In: Público. Produção: Dudu Marote. Direção Artística: Jorge Davidson. São Paulo: BMG, 2000. 1 CD. Faixa 7.

ESPINOSA, Bento de. Ética. Tradução Joaquim de Carvalho; Joaquim F. Gomes; António Simões. Lisboa: Relógio D’Água Editores, 1992. 501 p.

DELEUZE, Gilles. Espinoza e os signos. Tradução Abílio Ferreira. Porto: RÉS-Editora, [19-]. 202 p.

FOUCAULT, Michel. A escrita de si. In: O que é um autor? Tradução António Fernando Cascais; Edmundo Cordeiro. Portugal: Veja/ Passagens, 1992.

Leila Domingues Machado é Doutora em Psicologia Clinical Professora do Departamento de Psicologia da UFES/ Professora do Programa de Pós-Graduação em Política Social da UFES. $O$ endereço eletrônico da autora é: leiladomingues@uol.com.br

Leila Domingues

O desafio ético da escrita

Recebido: 8/12/2003

$1^{\text {a }}$ revisão: $5 / 3 / 2004$

Aceite final: 20/4/2004

150 